\title{
Cuerpos propios. Antagonismos en el arte de performance femenina en la época del giro performativo
}

\author{
Own Bodies. Antagonisms in the Art of Female \\ Performance at the Time of the Performative Turn
}

\section{RESUMEN}

El presente artículo traza un recorrido por algunas de las performances realizadas por mujeres artistas en los últimos 50 años en el ámbito artístico norteamericano, europeo y latinoamericano, cuyo significado gira en torno a la construcción patriarcal del cuerpo femenino. Obras que nos permiten reflexionar sobre la constante agresión y devastación a la que son sometidas las mujeres a través de la conquista y dominación de su cuerpo y que articulamos en dos epígrafes: cuerpos propios y cuerpos violentados. Con ello pretendemos aproximarnos al papel que ha desempeñado la performance, en la construcción o negación de los imaginarios culturales femeninos, en el seno del proceso de giro performativo que ha acometido la cultura desde los años sesenta, así como las lecturas historiográficas y los debates que en el seno del feminismo han generado dichas obras.

Palabras clave: historia del arte, género, arte contemporáneo, mujeres artistas, performance, giro performativo.

\section{Abstract}

This article traces an approach of some of the performances made by women artists in the last 50 years in North America, Europe and Latin America whose meaning involves the patriarchal construction of the female body. Artworks that allow us to reflect on the constant aggression and devastation to which women are subjected through the conquest and domination of their bodies and which we articulate in two sections: own bodies and violated bodies. With this we intend to approach the role played by performance, in the construction or denial of female cultural imaginaries, within the process of performative turn that culture has undertaken since the 1960s, as well as historiographical readings and debates that within the feminism have generated such works.

Keywords: Art history, gender, contemporary art, women artists, performance, performative turn.

\section{SUMARIO}

1.- Introducción. 2.- Cuerpos propios. 3.- Cuerpos violentados. - Conclusión. - Referencias bibliográficas. 


\section{Introducción}

El mundo no es solo un escenario, tampoco el teatro lo es del todo (Goffman, 2006: 9).

Vivir consiste en reducir continuamente el mundo al cuerpo, a través de lo simbólico que éste encarna. La existencia del hombre es corporal [...] Por estar en el centro de la acción individual y colectiva, en el centro del simbolismo social, el cuerpo es un elemento de gran alcance para un análisis que pretenda una mejor aprehensión del presente (Le Breton, 2002: 7).

Resulta sintomático que la mayoría de los discursos artísticos feministas que se desarrollaron en los años 70, década que evidencia la eclosión del arte feminista, lo hicieran desde el ámbito performativo, algo que implica per se toda una serie de cuestiones. La primera, se refiere a la capacidad que tiene el arte de acción para intervenir en la sociedad, su poder para determinar cambios en las prácticas sociales y culturales. Tal y como plantea Juan José Gurrola: «La performance no inaugura una realidad dentro de otra realidad como el teatro, sino que se incorpora a ella» (Alcazar, 2014: 1415).

La performance constituye un tipo de práctica que dinamita la frontera entre representación y realidad que caracteriza a otras disciplinas como la pintura o la escultura, en las que la separación se manifiesta de manera nítida. Esto es así ya que en el arte de performance el elemento discursivo lo conforma el propio cuerpo y la acción se desarrolla en vivo:

El performance sugiere una forma de praxis corporal que no solo reta la distinción entre experiencia y representación sino también cuestiona la frontera entre arte y teoría social (Alcazar, 2014: 1991).

Esa compleja imbricación entre realidad y ficción constituye, así mismo, un elemento que sitúa la performance en un marco de producción de realidad en el que el cuerpo del artista y la proyección de sus significados tiene una compleja manera de incidir en la sociedad. Esa dificultad estriba en el hecho que el público, que deviene parte integrante del acontecimiento, debe adoptar dos impulsos o actitudes: mantenerse en el marco de la teatralidad o en el de la interacción social.

Proveniente de la filosofía del lenguaje el término "performativo» fue reinventado por la teórica alemana Erika Fischer-Lichte (2011), quien concibió el concepto de giro performativo ${ }^{2}$, para referirse a un modelo que reemplazó al texto en su capacidad de aprehensión y comprensión del mundo, giro lingüístico, por el de las acciones y los acontecimientos, giro performativo, del que surgiría así mismo toda un teoría sobre la estética performática. Este cambio, puede ser observable en algunas propuestas teóricas de los años 60.

2 El término empleado en alemán Aufführung tiene una buena correspondencia en el término inglés performance, sin embargo «representación» en castellano no logra abarcar toda la complejidad que expresa en las otras dos lenguas, de manera que en castellano se ha hablado de "giro teatral», "giro performativo»o «realización escénica» indistintamente. 
El «giro teatral» en las ciencias sociales fue clave para comprender la configuración de la identidad como práctica de corporización. [...] Goffman y la vida cotidiana como escenificación; Baudrillard y la noción de simulacro; Debord y la sociedad del espectáculo; Turner y los ritos de paso (Vidiella, 2015: 112).

El propio Victor Turner junto a Richard Schechner fundarán en los años ochenta en la Universidad de Nueva York la línea de Estudios de Performance con la vocación de abordar el análisis de las prácticas performativas desde distintos ámbitos: rituales, culturales y artísticos. La performance tal y como opinaban estos autores se constituye como un modo de práctica que permite entender cómo y cuáles son los mecanismos de configuración de las subjetividades en la sociedad: «Representar no sólo implica indicar una realidad, sino recrearla, falsearla, resignificarla y recontextualizarla» (Vidiella, 2015: 112).

Si en el ámbito de las ciencias sociales el giro performativo tuvo una notable incidencia, no lo fue menos en el ámbito estético. Tal y como opina Victoria Pérez Royo (2010: 2-3), «el giro performativo implica sobre todo un cambio fundamental en la experiencia estética desde lo semiótico hacia lo performativo. El sentido de la obra no surge en la dialéctica hermenéutica entre significante y significado, sino en la creación de una vivencia para el espectador». Es así, como el proceso de lectura e interpretación de la obra artística se torna en experiencia compartida por parte del creador y el receptor. A ello se suma el indudable cambio que supuso la desmaterialiazción del objeto artístico como entidad física revisitable, en la que un receptor podía volver al encuentro de la obra artística ad infinitum para reencontrarse con los mismos o nuevos significados, contrariamente el giro performativo se fundamenta en su carácter efímero. Así mismo, otro de los elementos que ha contribuido a transformar la experiencia estética tras el giro performativo lo constituye el hecho que en la aprehensión estética entran en juego otras percepciones «no sólo intelectuales, sino también fisiológicas, afectivas, volitivas, energéticas e incluso motoras» (Pérez Royo, 2010: 2-3).

De todo ello se deduce la importancia que en las últimas décadas ha tenido la noción de performatividad en el seno, por ejemplo, de las teorías posestructuralistas. Nos referimos a las supuestas performatividades que autores como Foucault con sus tecnologías identitarias o Butler, entre otros, han desarrollado. Si las vanguardias contribuyeron a la fusión vida y arte, la performatividad posmoderna ha invertido el camino, haciendo que nuestro modus viviendi se infunda de la categoría representacional, el arte ha conquistado la esfera óntica. Ello, sin duda, genera toda una serie de problemáticas pues la autonomía del arte, esa condición que deniega la capacidad lógica y que fundamenta su mera existencia en su capacidad estética, ars gratia artis, sitúa también a nuestros actos en un peligroso lugar carente de juicio.

La segunda cuestión sobre la excelente aceptación que tuvo el arte de performance entre las mujeres artistas se refiere al carácter novel de la práctica artística. Al tratarse de una disciplina nueva no lastrada con los condicionantes del arte masculino que había definido a la pintura o la escultura, vetados durante siglos a la práctica femenina, el acceso de las mujeres contó con menos obstáculos y pudo hacerse desde presupuestos no aprendidos. 
Parte de la crítica historiográfica, sin embargo, ha ofrecido una sesgada lectura de la práctica del arte performativo de mujeres construyendo un relato que fundamenta la indisoluble adscripción de la mujer a lo corporal, como han denunciado algunas artistas. Una construcción que ha configurado una mitología del arte femenino como un arte experiencial, que trasciende las barreras de lo público y lo privado, ejercicio autoexploratio y autobiográfico y que manifiesta la superación de las fronteras del cuerpo objeto por el cuerpo sujeto. Disconformidad que se desprende de las palabras de la performer Regina José Galindo:

Me parece que el performance no es un campo que tenga que estar delimitado por una mujer [...] No entiendo porqué los medios tradicionales tienen que estar ligados al campo masculino y medios como la performance tengan que estar ligados al campo femenino. Creo que es una estrategia del sistema patriarcal el delegarte a ti siempre sólo a ciertos circuitos, es decir, las mujeres son buenas para trabajar con su cuerpo porque siguen manteniendo esa relación doméstica, corporal, pero los grandes medios -las piedras, las esculturas- se siguen elaborando por los grandes maestros. No hay que caer en el error de seguir el juego a esas premisas (Sancho, 2014: 140).

Si bien dichos encasillamientos coaccionan los límites artísticos, no es menos cierto que el ejercicio de encuerpamiento (embodiment) y de empoderamietno (empowerment) que posibilitó el arte de acción contribuyó y ha contribuido, en mucho, a la consecución de un discurso propio.

\section{Cuerpos propios}

A finales de los años 60 algunas performers pioneras comienzan a abordar en Europa y en Estados Unidos, una serie de piezas en las que observamos un nexo común, la voluntad de ejercer el uso del cuerpo como un acto de empoderamiento, en un proceso de subjetivización del cuerpo-objeto. La aparente libertad con la que estas autoras despliegan su propio cuerpo al público, constituye un ejemplo más del carácter antagónico que desprende la práctica performativa: el objeto se torna sujeto para devenir nuevamente objeto.

En 1968 la artista austríaca Valie Export realiza la pieza Action pants genital panic. Se trataba de una acción en la que la artista irrumpía en un cine porno vestida con unos pantalones con la costura descosida en la entrepierna que dejaba al descubierto su pubis y su vagina. La artista paseaba por la sala sosteniendo una metralleta y asaltaba a unos espectadores acostumbrados a mirar genitales en la pantalla desde una posición segura. La imagen se hacía carne y atentaba contra la reciprocidad visual (Berger) de unos observadores que objetualizan y sexualizan el cuerpo de la mujer en un acto en el que quieren ver pero no ser vistos.

En otra acción Tap and touch cinema (1968) la artista recorría las calles con una caja con una cortinilla frontal que reproducía la morfología de un pequeño teatro y que escondía sus pechos desnudos invitando a la gente a tocarlos y manosearlos a su antojo (Warr, 2000; Reckitt, 2001). Pareciera que la artista desafiara las lindes 
de lo teatral y lo real, sin embargo, el espacio locativo de la calle, ajeno al espacio escénico, generaba el consecuente extrañamiento entre el público ${ }^{3}$.

En este caso el marco en el que se desarrolla la acción tal y como exploró Irving Goffman (2006) en su teoría de los marcos, nos incita a proyectar un significado sobre el significante. Al hacer representacional el acto de manosear los pechos de una mujer por invitación expresa de ésta en el marco de una acción performativa, estamos interviniendo en el significado que otorgaríamos a ese mismo acto en el marco de otro ámbito de significación. La categoría voluble que presenta la performance como acto de presencia y representación a un mismo tiempo impide en muchas ocasiones al espectador establecer un criterio definido de marco, y como apuntamos unas páginas más arriba, sitúa al espectador en la constante diatriba de mantenerse en el marco de la teatralidad o en el de la interacción social y atribuir, así, unos significados u otros.

De manera similar Marina Abramovih se embarcaba en una serie de performances en las que su propia integridad, física y psíquica, era precipitada al abismo. En Rhythm 0 realizada en 1974, la artista disponía 72 objetos ${ }^{4}$ que podían ser utilizados por el público a su antojo, el cuerpo de la artista se convertía en la superficie sobre la que proyectarlos. Contemplamos en estas acciones la disyuntiva del sujeto que deviene objeto y el objeto que deviene sujeto indistintamente (Barthes) que definió al arte de performance. Durante las seis horas que duró la acción, el cuerpo de Abramovic fue ultrajado de las más diversas maneras: reubicada en una mesa con las piernas abiertas y un cuchillo aproximado a sus genitales, herida con un corte en el cuello que le practicó un espectador y que bebió su sangre, apuntada con una pistola cargada, que tuvo que ser interceptada por los vigilantes de la sala. En esta performance se evidencia la relación de cosujetos que establece Fischer-Lichte entre performer y espectador, la copresencia física en un mismo espacio convierte a ambos en actores de un mismo acontecimiento.

Para Kathy O'Dell (1998) $)^{5}$ las obras de los años 70 asumieron un destino inmolatorio como mecanismo de expresión y posicionamiento crítico. Las teorías de la psicología de Lacan y Didier Anzieu y su Yo-piel (1985), estuvieron en el trasfondo, sin duda, de muchas de estas prácticas, que ofrecieron cuerpos al sacrificio del ritual artístico.

3 En la actualidad la artista Milo Moiré ha reinterpretado la pieza de Export rebautizada como Mirror box. Mientras desarrollaba la acción en Londres en 2016 fue detenida.

4 Un látigo, un libro, pan, un cuchillo, unos zapatos, un hacha, vino, unas tijeras, un peine, uvas, un martillo, clavos, un trozo de madera, azúcar, agua, un espejo, una pistola, una pluma, un periódico, pintura roja, una manzana, sal, una bala, pintura blanca, un lápiz de labios, un frasco de perfume, una medalla, una cuchara, una flauta, un abrigo, una campana, un sombrero, un bastón, agujas, un pastel, una boa de plumas, una bufanda, una vela, un pañuelo, cadenas, un broche para el pelo, un hueso de cordero, unas flores, un tenedor, un cuchillo de bolso, una rama de romero, pintura azul, algodón, alcohol, cerillas, una banda adhesiva, una caja de cuchillas de afeitar, una silla, un escalpelo, una rosa, jabón, hilo, cuerdas de cuero, una pipa, un broche de seguridad, una pluma de ave, vendas, una lanza de metal, una sierra, un folio, un plato, azufre, aceite de oliva, alambre, un vaso, miel y una cámara Polaroid.

5 O'dell habla de «trabajos masoquistas» para referirse a los ejemplos de Chris Burden, Vito Aconcci, Gina Pane, Ulay y Abramovic. 
Prácticas corporales que mantenían, también, una estrecha relación con el teatro de la crueldad de Antonin Artaud y lo ritual-catárquico. Explorar los límites de lo irracional que aportaba lo natural, lo mágico, lo onírico, el trance y el inconsciente, fue también una respuesta crítica en los años 70 frente a la racionalidad de la modernidad. Los límites del cuerpo y con este todas las fronteras epistemológicas que de él derivan fueron puestos en cuestionamiento y es en esa frontera entre el cuerpo como vehículo discursivo y el cuerpo como campo de batalla (Kruger), en el que se insertaron las difíciles líneas ontológicas de la práctica performativa. Evidentemente, la performance y el body art como arte encarnado ofrecen una nueva manera de dominación hacia el objeto artístico y encuerpan la relación entre artista, obra y público, como hemos observado en los ejemplos que hemos planteado en los que el cuerpo de la mujer aparece profanado de manera directa, en la mayoría de los casos, por el espectador hombre.

A partir de los años 80 observamos un viraje en la utilización del cuerpo como plasmación de la sexualidad femenina. Hemos de situar estas prácticas en el seno de los discursos que en torno a la sexualidad se desarrollaron en el pensamiento feminista en esa misma década.

En el año 1976 en Londres al calor de las propuestas que el punk desarrollaba en la ciudad, el colectivo COUM formado por la artista Cosey Fanni Tutti y Genesis P-Orridge escandalizaban con la exposición Prostitution desarrollada en el Institute of Contemporary Art de Londres. En ella se mostraban fotografías y documentos relativos a las actividades performativas como modelo pornográfica de Cosey Fanni Tutti, aspecto que motivó la prohibición para el colectivo de exponer en Inglaterra en ningún otro espacio o galería (Goldberg, 2002: 182).

La libertad sexual, la sexualidad femenina y la pornografía se constituyeron como uno de los caballos de batalla desde finales de los años 70 y particularmente en los 80. Una cuestión que según Raquel Osborne (1993) dividió al movimiento feminista y al que algunas autoras intentaron dar resolución, explorando la difícil relación entre sexualidad y peligro. Para Osborne era necesario superar la monoidea crítica a la pornografía y plantearse otras variables que no determinaran la sexualidad como la causante de todos los males que afligían a las mujeres. La constatación que en el binomio sexo-mujer se halla el origen de la construcción patriarcal, no implicaba una condena hacia la sexualidad como exclusiva causa de la opresión femenina. La cuestión debía girar en torno a planteamientos que permitieran aunar ambos criterios: «¿cómo combinar la lucha contra los abusos sexuales masculinos con la libertad sexual de las mujeres? ¿Cómo podemos apoyar la libertad sexual sin legitimar por ello los aspectos más opresivos de la conducta sexual masculina?» (Osborne, 1993: 26).

La artista Hannah Wilke se hacía eco de las disidencias en el seno del feminismo con su cartel Beware of facist feminism para referirse a un grupo que osciló a posturas coincidentes con políticas conservadoras en lo referente a la sexualidad femenina.

Como eco de todos estos discursos en los años 90 la stripper y actriz porno Annie Sprinkle desarrolla el término «posporno» para referirse a nueva manera de entender la pornografía, por parte de algunas mujeres. Una corriente que recogía la 
voluntad de resignificación, visibilidad y creatividad pornográfica para el cuerpo y el deseo femenino. En la performance The Public Cervix Announcement (1993), la artista invitaba al público a examinar el interior de su vagina a través de un espéculo, desafiando los límites de lo privado y lo público, lo interno y lo externo, el Placer y el Peligro 6 (Vance, 1984).

La relación entre pornografía y género ha sido una cuestión que, como hemos observado, ha despertado y despierta, todavía hoy, constantes antagonismos, debates e incomodidades pues el lastre de la construcción patriarcal y el estigma que le precede hace difícilmente tolerable su práctica para buena parte del pensamiento feminista:

[...] reinventar la pornografía. Emilie ${ }^{7}$ se pregunta si no debiéramos crear otro nombre para designar la representación explícita de la sexualidad, dado que el término pornografía está tan contaminado de sexismo. Y el prefijo pos tal vez no sea una modificación suficiente para borrar décadas de representaciones unidireccionales (Llopis, 2010: 16-17).

En la actualidad han surgido algunas propuestas como la de Diana Torres, que recuperando el legado del punk de los años 70 y el posporno de los 90, ha elaborado el nuevo concepto de Pornoterrorismo: «Lo pornográfico me interesa porque veo en el cuerpo y en la sexualidad armas muy poderosas para destruir este sistema, lo pornográfico es la forma de representar ese cuerpo y esa sexualidad. Hoy en día cualquier representación que no respete las reglas prácticas y estéticas, es terrorista» (Torres en Noyola, 2015).

Lo cierto es que lejos de abandonarse, las propuestas referentes a la sexualidad femenina continuaron y se fundieron con otros planteamientos académicos. En los años noventa a los discursos políticos se añadieron los teóricos sobre la construcción de la mirada, que objetualiza, domina y posee el cuerpo femenino, un sistema panóptico de control y disciplina que dieron como resultado toda una serie de piezas performativas que versarían sobre la sexualidad femenina fuera del marco de la privacidad.

En 1992 la artista mexicana Rocío Boliver, acometía una serie de acciones en las que leía en voz alta textos con carácter sexual escritos por ella como: «A la conquista del chocho mis valientes». En una de estas acciones la artista se masturbó en público introduciéndose en la vagina un refresco con sabor a uva. Explorar su deseo y hacer pública y explicita su sexualidad estuvieron en el ideario de las performances de Boliver como estrategia estética:

Exhibe su cuerpo desnudo de manera explícita, abyecta y grotesca, como un reto a la hipocresía reinante [...] Confronta el voyerismo en un exhibicionismo franco y desinhibido que da visibilidad a todas sus partes del cuerpo, pero

6 Actas del simposio celebrado en torno a cuestiones sobre la sexualidad femenina en 1984 en el Barnad College, Nueva York.

7 Se refiere a Emilie Jouvert, directora de películas porno lesbiano y queer. 
privilegia sus órganos sexuales a los que siempre pone en primer plano (Alcazar, 2014: 3340).

En su afán por deconstruir los modelos sobre los que se ha asentado la sexualidad femenina desde la cultura patriarcal, Boliver emprende procesos de apropiación y resignficación de términos como el de «puta», al que confiere un valor diferente como ejercicio subversivo, práctica no exenta de antagonismo. Mediante acciones en las que aparece con objetos introducidos en su vagina y su ano, contribuye según la artista a des-erotizar estos órganos y con ello a derribar las férreas construcciones que condicionan el cuerpo de la mujer.

Estas acciones nos sitúan nuevamente en las movedizas arenas del arte performativo. La performance es un arte autorreferencial, significa lo que se hace y constituye realidad porque crea la realidad social que expresa.

Otra artista que ha explorado los límites de la mirada y la sexualidad femenina es Elke Krystufek. En 1996 realizaba la performance Satisfacción en la Kuntshalle de Viena. En ella la artista desarrollaba una serie de actos íntimos: tomaba un baño, se aseaba y luego se tendía en una toalla donde se masturbaba con un vibrador. Todo ello sucedía ante la atenta mirada de un público que se disponía tras un cristal observando la acción como si de un experimento se tratara. Mediante esta tecnología Krystufek activaba el mecanismo de la mirada escoptofílica (Mulvey) que objetiviza y sexualiza al cuerpo observado, normalmente el de una mujer. El ambiente clínico y aséptico de la sala donde acontecía la acción tenía como propósito deconstruir la naturalidad del cuerpo. Un acto placentero que deviene clínico, reforzado por las direccionales miradas que construyen también el cuerpo de la artista: «By enacting her private rituals in a public space, she opened up issues of intimacy, authenticity and sensationalism, forcing the viewer to confront his/her own position as voyeur» (Warr, 2012: 111).

Siete años más tarde en 2003 la performer norteamericana Andrea Fraser iba un paso más allá. En la pieza Untitled, la artista ponía a la venta su cuerpo por $20.000 \$$ para mantener una relación sexual con un coleccionista que actuaba como comprador de la obra, en este caso la propia Fraser.

Lo acontecido en la habitación del hotel donde se desarrollaba la acción era registrado por un video de 60 minutos del que tan solo cinco copias fueron puestas a la venta, una de ellas fue adquirida por el coleccionista que protagonizaba la cinta junto a Fraser, el resto se hallan en la actualidad en colecciones privadas, si bien la artista se reservó el derecho de exigir una serie de condiciones legales para que la obra no fuera sobreexplotada. Untitled fue comisariada por la galería Friedrich Petzel y reproducida por primera vez en la retrospectiva consagrada a la artista en el Museo Ludwig de Colonia en 2013.

Al desprenderse del público para realizar su acción Fraser se escondía y parapetaba en el espacio de lo privado y devolvía al público a la categoría de observador pasivo, rasgo que la diferencia de las performances referidas con anterioridad en las que el público contempla la acción en vivo y se convierte en cosujeto del acontecimiento (Fischer-Lichte, 2011). 
Según Fraser, el acto tenía una finalidad específica: «not for sex [...] but to make an art work» (Fraser en Saltz, 2009). Con ello la artista pretendía evidenciar la relación y el estatus de sumisión de las mujeres artistas con el mercado del arte, un estado de prostitución efectivo que reproducía las relaciones de dominio asimétricas hombre-mujer.

Del mismo modo que el arte no puede existir fuera del campo del arte, tampoco nosotros podemos existir fuera de él, por lo menos no como artistas, críticos, comisarios, etc. Y lo que hagamos fuera de ese campo, en la medida que permanece afuera, no puede tener efectos dentro. Es decir, que si no hay un afuera para nosotros, no es porque la institución está perfectamente cerrada [...] Es porque la institución está dentro de nosotros. Y nosotros no podemos salir de nosotros mismos (Fraser, 2016: 20-21).

El marco referencial ejercía el poder de resignificar los actos que allí tenían lugar, el significado operaba más allá de su mera referencialidad, para erigirse en alegoría o metáfora de algo más. Sin embargo, la difícil relación entre objeto y sujeto que plantea la performance como disciplina suscitaba reflexiones que iban más allá de la mera condición artística.

Sea como fuere, la propuesta de Fraser, como era de esperar, desató las más airadas críticas, aunque por motivos distintos, desde frentes tan radicalmente opuestos, como el feminismo y el establishment del mercado del arte.

Otra cuestión bien distinta es el posicionamiento feminista que podría desprenderse de su obra. La artista se refería a esta cuestión de la siguiente manera:

Is «Untitled» a feminist piece? Is it an anti-feminist piece? Is it a post-feminist piece? I don't feel that I've really worked through that question [...] My own experience of doing the piece was really very empowering and quite in line with my understanding of my own feminism [...] I never felt used by the collector. In fact, I was much more concerned about using him. And showing it has also been empoweringterrifying, but empowering. [...] I think it's sort of ridiculous to say that the piece was prostitution [...] but it really was a very different kind of relationship, one in which I had an enormous amount of power (Fraser en Praxis, 2004).

Esta afirmación de la artista merece una reflexión más detenida. En primer lugar, cabría destacar que no deja de ser una cuestión harto asombrosa que la propia autora manifieste no haber reflexionado sobre si su obra era una pieza feminista cuando su intencionalidad es denunciar el estado de prostitución simbólica de las mujeres artistas con respecto a los hombres en el mercado del arte:

[...] la difusión de estos discursos postfeministas se estaban llevando a cabo rodeadas de un aura que, a costa de borrar del mapa a buena parte de las autoras feministas, pretendía colocar el postfeminismo como el nuevo y verdadero feminismo del presente (Arakistain, 2009).

Un feminismo sin feminismo o feminismo antagónico que amparado en el espejismo de la igualdad intentaba despolitizar los discursos. Apelar al posfeminismo 
sería como apelar al pospatriarcado y éste, lejos de manifestar algún tipo de evolución, se mantiene anclado en su misma idiosincrasia.

En segundo lugar, la fatua pieza de Fraser trasluce algunas cuestiones de calado mayor: ¿Es la libertad de elección el fundamento angular de la práctica feminista? ¿Es el arte patente de corso para que cualquier tipo de práctica pueda ser desarrollada, ars gratia artis, acaso el propósito de la acción enmascara que el hecho que se pone en práctica finalmente es una transacción económica en la que se vende un cuerpo femenino? ¿Existe una ética para la estética que difiere de la ética en el mundo social o nulla aesthetica sine etica?:

La autonomía del arte se convierte en objeto de autorreflexión de las realizaciones escénicas, incluso cuando llevan al desplome una y otra vez a las oposiciones ente arte y realidad, entre lo estético y lo no-estético. Precisamente el desmantelamiento de estas contraposiciones, su amalgamiento, se puede considerar como una de los resultados de las reflexiones sobre la autonomía del arte llevaba a cabo por las realizaciones escénicas, en las que de consuno se cuestiona radicalmente esa misma autonomía (Fischer-Lichte, 2011: 342).

El Teatrum mundi neobarroco de la posmodernidad ha contribuido, sin duda, a que buena parte de los comportamientos sociales incluidas las prácticas artísticas se adapten al imperativo performativo al que autoras como Butler (2001: 177) otorgan una inmensa capacidad de acción para el sujeto, no en vano la propia Fraser formada en la interpretación ha mantenido siempre sus performances como trabajos interpretativos. Si las vanguardias articularon «la disolución de la frontera entre el arte y la vida y la eliminación del arte como una esfera separada de la cotidianeidad» (Pardo, 1999: 15), la performance de Fraser nos devuelve nuevamente a esa frontera en la que la teatralización marca el límite de la vida y la representación. Amparados en el relativismo posmoderno las prácticas artísticas y las sociales se desprenden de sus implicaciones en el ámbito de la significación, por más que, como opina Ana de Miguel (2015: 59) respondiendo a Butler: «Ser una mujer no es una performance es una posición subordinada dentro de un sistema jerárquico de poder»; y porque como opinaba Goffman (2006: 9)en la cita inicial de este trabajo, «El mundo no es solo un escenario, tampoco el teatro lo es del todo»:

Si las realizaciones escénicas se aproximan a la vida [...] entonces [...] hay una cierta probabilidad de que los parámetros que no pueden aplicarse a ellas tampoco puedan aspirar a tener validez para el conocimiento y la descripción de la vida (Fischer-Lichte, 2011: 347).

Con todo cabría plantearse si las respuestas que provocaron las obras de Boliver, Sprinkle, Kristufek o Fraser fueron semejantes a las que suscitaron las performances en las que Vito Acconci o Chris Burden, entre otros, realizaban actos sexuales públicamente como manifestación artística. Creemos a todas luces que no. Ello nuevamente nos hace reflexionar sobre el valor discursivo que se 
atribuye a lo masculino pues Aconcci y Burden eran hombres-cuerpos-sujetos con autoridad y voz que actúan, mientras que en el otro caso son mujeres-cuerpoobjeto que muestran, por más que tras sus performances traslucieran, como en el caso de los dos primeros, una clara intencionalidad artística y crítica.

\section{Cuerpos violentados}

La violencia simbólica y la violencia física han constituido los grandes baluartes sobre los que se ha construido el régimen de dominación patriarcal, en ese sentido también toda una serie de prácticas performativas fueron desarrolladas desde los años 70 para referirse a esta lacra que afectaba y condicionaba la vida de las mujeres sin distinción.

En 1972 la artista cubana afincada en Nueva York Ana Mendieta realizaba la performance Cristal sobre cuerpo. Según María Ruido (2000: 8):

La artista experimenta los límites de la carne al exprimirla y violentarla simbólicamente contra el cristal, un elemento transparente y aparentemente inapreciable (como el mismo sistema ideológico generador de las tecnologías de dominio corporal), pero eficazmente duro y resistente.

Cuerpos medidos, mesurables como se deduce de la serie de performances en torno a los cuerpos métricos que caracterizaron a distintas artistas en los años 70 como Ester Ferrer Íntimo y personal (1971); Eleanor Antin Talla una escultura tradicional (1973) o Martha Rosler con Vital Statistics of a citizen, simply obtained (1977).

Durante los años 70 se sucedieron toda una serie de obras que denunciaban la agresión física sobre las mujeres:

Las mujeres son asesinadas o violadas por el simple hecho de ser mujeres [...] la violencia contra las mujeres tiene importantes consecuencias en su sociabilización (De Miguel, 2015: 47).

Ana Mendieta abordaba la cuestión de las agresiones sexuales a mujeres con varias piezas. En 1973, en Autorretrato con sangre la plasmación de la agresión se mostraba en un plano frontal sin eufemismos ni conceptualismos. En Gente mirando sangre, la artista creaba una situación, los viandantes de una calle se topaban con un rastro de sangre que permanecía en la acera, indicio de una agresión. En Mujer atada el cuerpo de la artista que aparecía con las manos y los pies atados a la misma cuerda por la espalda se retorcía con esfuerzo por desprenderse. Por último, Escena de violación mostraba el cuerpo desnudo de Mendieta atado y postrado en una mesa, como opinaba María Ruido (2000: 34): « [...] ambas escenificaciones nos confrontan, en su misma calidad de re-construcción distanciada, marcadamente no-realista, con nuestro papel de cómplices $\mathrm{y}$ actores de la violencia cotidiana».

En este caso la condición de cosujetos (Fisher-Lichte, 2011) se conjuga en nuestra condición de actuantes no en el acontecimiento creado por la artista sino en la vida real. 
También en estados Unidos en 1977 las artistas norteamericanas Suzane Lacy y Leslie Labowitz realizaban las acciones Con luto y con rabia y Tres semanas en mayo. En la primera de ellas las asistentes denunciaban el tratamiento que los medios sensacionalistas dedicaban a las noticias sobre violaciones y asesinatos de mujeres. En la segunda marcaban con la palabra violación en un mapa de la ciudad de Los Ángeles los lugares en los que se había cometido una agresión sexual contra una mujer, en lo que se manifiestan como una geografía urbana de la violación y que constituye desde nuestro punto de vista, también, una crítica a la psicogeografía situacionista francesa de marcado carácter masculino.

La elusión del cuerpo de la mujer en las piezas de Lacy y Labowitz, que no así de Ana Mendieta, y el tratamiento semiótico de la violación como texto, es un aspecto que a nuestro juicio, marca una diferencia con las aproximaciones al mismo tema por parte de las performers latinoamericanas.

Efectivamente, en las últimas décadas encontramos en el arte latinoamericano una profusión de mujeres que hacen uso de la performance como manifiesto crítico. Siendo frecuente en ellas la relación entre la devastación producida por los conflictos armados que asolan el territorio latinoamericano y los feminicidios y el propio cuerpo de la mujer que se establece como una prolongación de la conquista territorial ${ }^{8}$.

En Territorio mexicano (1997) Lorena Wolfer genera una situación en la que el público escucha un discurso de un senador norteamericano aludiendo a la lucha contra el narcotráfico en México, acto seguido penetra en una sala convertida en quirófano clínico en cuyo centro y envuelto en una espesura de humo el cuerpo de Wolfer aparece atado y extendido en una camilla mientras una bolsa de sangre gotea su contenido y se desliza por su vientre durante horas, metáfora de un territorio que se desangra.

Una de las autoras que mejor define la proyección del cuerpo propio como cuerpo colectivo femenino en Latinoamérica es la artista guatemalteca Regina José Galindo. Una de las primeras performances de Galindo fue Dolor en un pañuelo (Figuras 1 y 2), en esta acción el cuerpo de la artista servía de superficie de proyección de toda una serie de noticias sobre violaciones y agresiones sexuales a mujeres en Guatemala. Esta obra nos parece un excelente reverso del aspecto que apuntábamos en párrafos anteriores sobre el diferente tratamiento de la violación, pues a diferencia de la pieza de Lacy y Labowitch en la que la palabra y el mapa se constituían como ejemplos del giro semiótico, en la propuesta de Galindo se evidenciaba, además, la pujanza del giro corporal.

Destacaríamos como última pieza de este recorrido por la performance femenina, por su enorme poder de denuncia, la pieza de Regina José Galindo 279 golpes (Figuras 3 y 4). Una performance sonora en la que tal y como explicaba la artista:

8 La idea de conquista territorial y conquista corporal está en la base de los principios del ecofeminismo. Tal y como planteaba Françoise d'Eaubonne, el patriarcado se caracteriza por un régimen de explotación y conquista; explota la fertilidad de la mujer, de la tierra y de los animales. Así lo considera también Puleo (2011: 16): «El ecofeminismo pretendía transformar y sustituir el modelo androcéntrico de desarrollo, conquista y explotación destructivos». 
«Encerrada en un cubículo, sin que nadie pueda verme, me doy un golpe por cada mujer asesinada en Guatemala del 1 de enero al 9 de junio del 2005. Amplifico el sonido, para que sea escuchado desde afuera del cubículo» (Galindo, 2005).

\section{Conclusión}

La performance ha constituido un excelente reflejo de la realidad femenina. El carácter representacional que caracteriza a la performance no la relega al ámbito ficcional, como hemos intentado evidenciar, su carácter autorreferencial la sitúa, también, en el ámbito de la construcción de realidad.

Es por ello que las vicisitudes, preocupaciones, pulsiones y denuncias que las mujeres han realizado a través de lo performativo han tenido una correlación e incidencia directa con y en los discursos que el feminismo ha desarrollado en las esferas de la vida, la política o la academia (Medina-Vicent y Reverter-Bañón, 2016), entre otras.

Los procesos de igualdad, diferencia, libertad y resignificación que han caracterizado la historia del feminismo se ven claramente reflejados en las obras que hemos mostrado, así como en las respuestas que éstas han generado. Del poder discursivo y del carácter expresivo de la performance como arte da buena cuenta, sin duda, la excelente aceptación que la práctica tuvo en el seno del arte para muchas mujeres, tal y como se desprende en estas páginas.

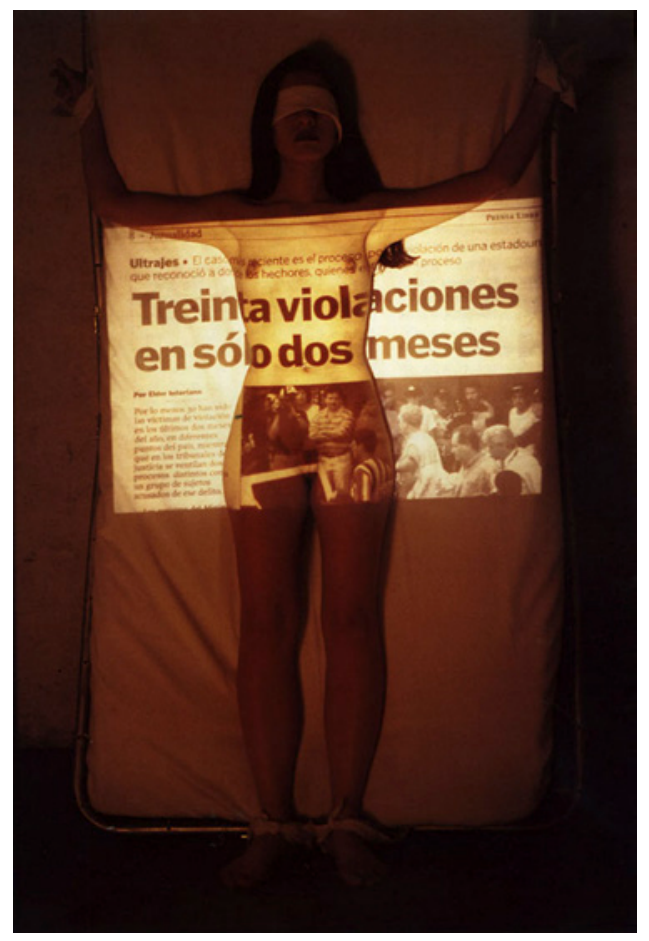

Fig. 1. Dolor en un pañuelo (Regina José Galindo, 1999). @ Regina José Galindo (cortesía de la artista). 


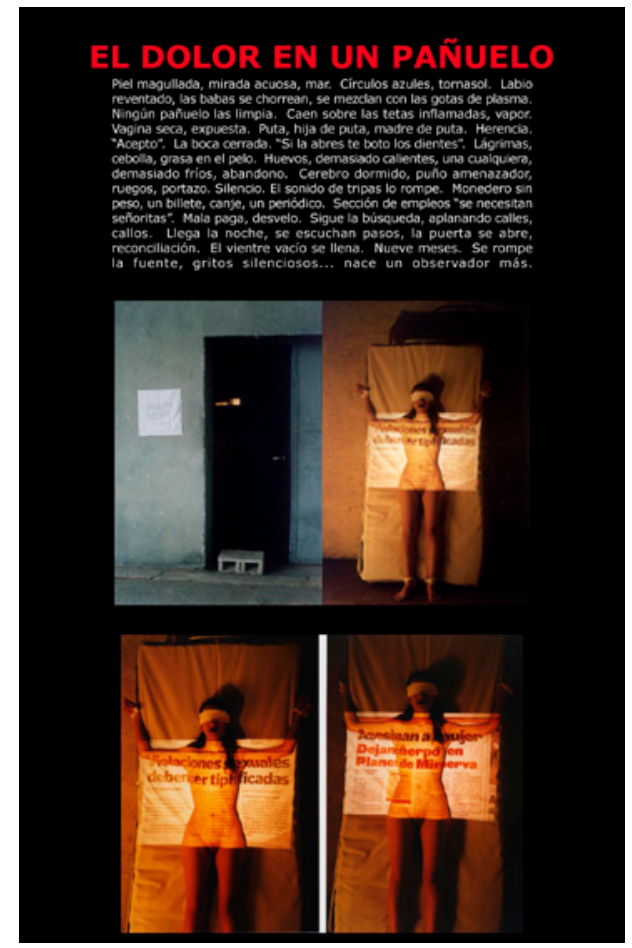

Fig. 2. Dolor en un pañuelo (Regina José Galindo, 1999). @ C Regina José Galindo (cortesía de la artista).

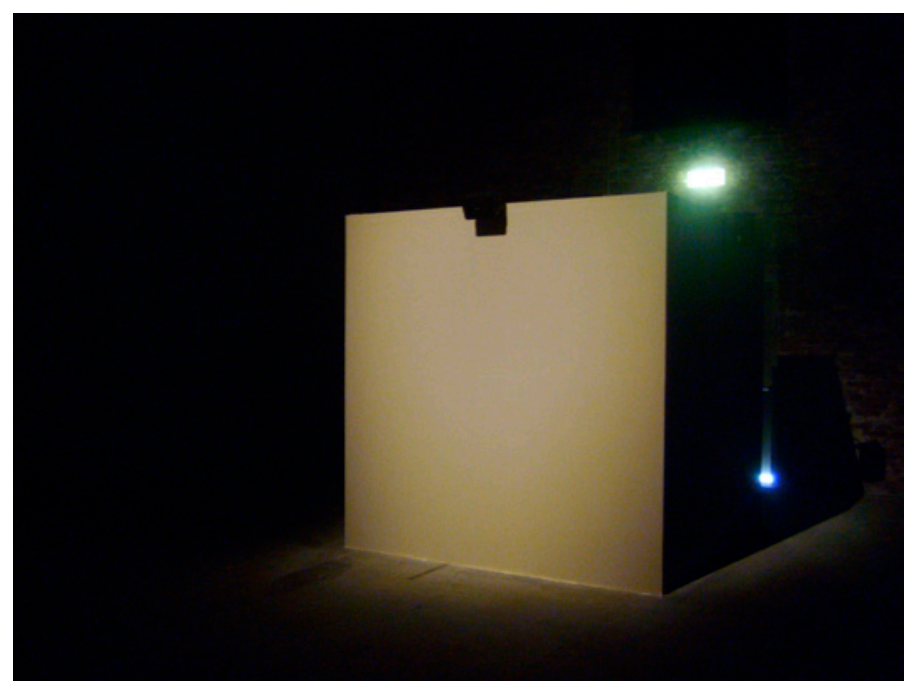

Fig. 3. 279 golpes (Regina José Galindo, 2005). @ Regina José Galindo (cortesía de la artista). Performance-instalación. 


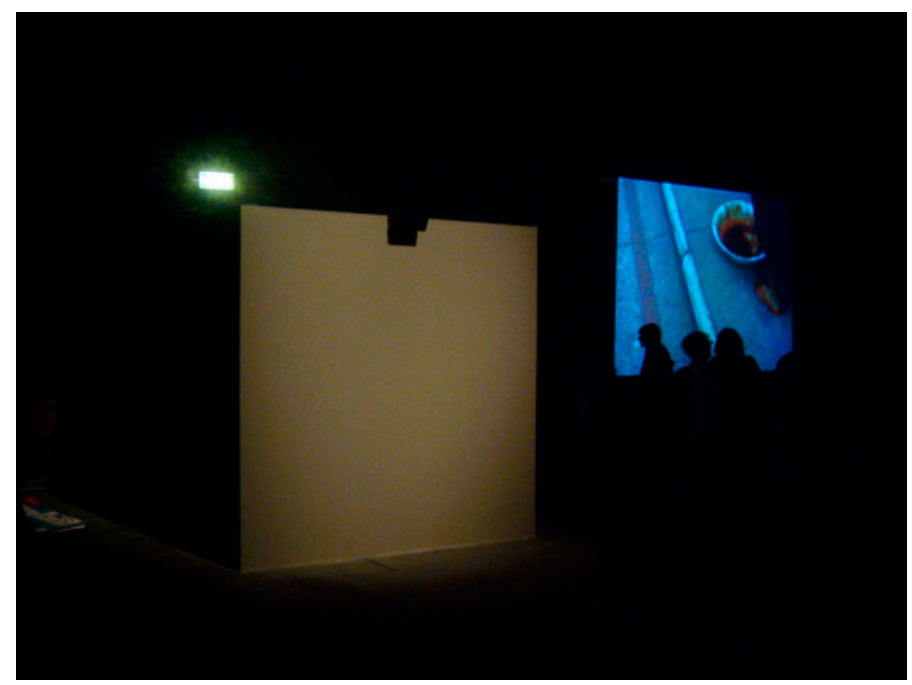

Fig. 4. 279 golpes (Regina José Galindo, 2005). @ Regina José Galindo (cortesía de la artista). Performance-instalación.

\section{REFERENCIAS BIBLIOGRÁFICAS}

Arakistain, Xavier (2015). «De la producción artística de Elke Krystufek y de la construcción de una nueva mirada feminista» en VALIE, Export y Silvia EIbLMaYr (eds.) (2015). Elke Krystufek. Dorit Margreiter. Franziska \& Lois Weinberger. Österreich Pavillon, 53. Internationale Kunstausstellung - La Biennale di Venezia. Verlag der Buchhandlung Walther König: Köln.

Alcazar, Josefina (2014). Performance un arte del yo, Autobiografía, cuerpo e identidad, Buenos Aires: Siglo XXI.

Anzieu, Didier (1985). Le moi peau, Dunod: Paris.

ButLer, Judith (2001). El género en disputa, Barcelona: Paidós.

De Miguel, Ana (2015). Neoliberalismo sexual. El mito de la libre elección, Madrid: Cátedra.

FisCHER-LICHTE, Erika (2011). Estética de lo performativo, Madrid: ABADA Editores.

FrASER, Andrea (2016). Andrea Fraser, de la crítica institucional a la institución de la critica, Mexico: Siglo XXI.

Galindo, Regina José (2005). «279 golpes». Disponible en: http://www. reginajosegalindo.com/279-golpes / (Fecha de consulta 15/03/18).

Goffman, Erving (2006). Frame Analysis. Los marcos de experiencia, Madrid. Siglo XXI.

Goldberg, Rosalee (2002). Performence Art, Barcelona: Destino.

Le Breton, David (2002). Antropología del cuerpo y modernidad, Buenos Aires: Nueva Visión.

Llopis, María (2010). El posporno era eso, Madrid: Melusina. MedinA-vicent, Maria y Sonia REVERTER-BAÑón (2016). «La perspectiva de género como una crítica al mundo» en Asparkía. Investigació feminista, No29, pp. 11-16. 
Noyola, Carlos (2015). «El espectáculo de la masturbación anticapitalista». Disponible en: https://www.viceversa-mag.com/diana-torres-el-espectaculode-la-masturbacion-anticapitalista/ (Fecha de consulta 15/03/18)

O'DELL, Kathy (1998). Contract with the skin, Minessota: University of Minnesota Press.

Osborne, Raquel (1993). La construcción sexual de la realidad, Madrid: Cátedra.

PArdo, José Luis (1999). «Prólogo» en Debord, Guy (1999). La sociedad del espectáculo, Valencia: Pre-textos, pp. 9-31.

Pérez Royo, Victoria (2010). «El giro performativo de la imagen» en Signa. Revista de la Asociación de semiótica, N¹9, pp. 143-158.

PrAXIs (2004). «Andrea Fraser», en The Brooklyn rail. Critical perspectives on arts, politics, and culture. Disponible en: https://brooklynrail.org/2004/10/art/ andrea-fraser (Fecha de consulta 15/2/18).

Puleo, Alicia (2011). Ecofeminismo para otro mundo posible, Madrid: Cátedra.

Reckitt, Helena (ed.) (2001). Art and feminism, Nueva York: Phaidon.

RAMíreZ BLANCO, Julia (2010). «Regina José Galindo o el cuerpo como nación» en Boletín de Arte, No30-31, pp. 519-532.

Ruido, María (2000). Ana Mendieta, Nerea: Hondarribia, Guipúzcoa.

SALtz, Jerry (2009). "Critiques interruptus», en The village voice. Disponible en: https://www.villagevoice.com/2007/02/13/critiqueus-interruptus/ (Fecha de consulta 15/2/2018).

SANCHO, Lidón (2014). «La investigación sobre la construcción sociológica, educacional y de género del mundo actual a través de la obra de Regina José Galindo» en Dossiers feministes, Nº19, pp. 135-147.

SERnA, Justo y Anaclet Pons (2005). La historia cultural. Autores, obras, lugares, Madrid: Akal.

Smith, Sidonie y Julia Watson (2002). Interfaces Women, Autobiography, Image, Performance, Michigan: The University of Michigan Press.

VAnce, CARole S. (1989). Placer y peligro. Explorando la sexualidad femenina, Madrid: Talasa Ediciones.

Vidiella PAgÉs, Judit (2015). «Sobre el giro educativo y los "gestos" de mediación en el territorio artístico» en AlbarRán, Juan y Iñaki Estella (eds.) (2015). Llámalo performance: historia, disciplina y recepción, Madrid: Brumaria, pp. 97-138. WARr, Tracey (ed.) (2000). The artist's body, Nueva York: Phaidon.

Recibido el 26 de marzo de 2018

Aceptado el 3 de septiembre de 2018 BIBLID [1132-8231 (2018): 117-132] 